\title{
The Observation of Double Gyroid and Hexagonally Perforated Lamellar Phases in ABCBA Pentablock Terpolymers
}

Jia Gao, ${ }^{\dagger}$ Chao Lv, ${ }^{\dagger}$ Kun An, ${ }^{\dagger}$ Xiaoying Gu, ${ }^{\perp}$ Jingjing Nie, ${ }^{\ddagger}$ Yongjin $\mathrm{Li}_{,}{ }^{\perp}$ Junting $\mathrm{Xu},{ }^{\dagger}$ and

$$
\text { Binyang Du }{ }^{\dagger *}
$$

\footnotetext{
${ }^{\dagger}$ MOE Key Laboratory of Macromolecular Synthesis and Functionalization, Department of Polymer Science \& Engineering, Zhejiang University, Hangzhou 310027, China

${ }^{\ddagger}$ Department of Chemistry, Zhejiang University, Hangzhou 310027, China

${ }^{\perp}$ College of Material, Chemistry and Chemical Engineering, Hangzhou Normal University, Hangzhou 310036, China
}

\section{Contents:}

1. The ${ }^{1} \mathrm{H}$ NMR spectra and GPC traces of $\mathrm{S}_{62} \mathrm{O}_{46} \mathrm{~S}_{62}, \mathrm{~S}_{60} \mathrm{O}_{90} \mathrm{~S}_{60}$ and $\mathrm{S}_{65} \mathrm{O}_{136} \mathrm{~S}_{65}$ triblock copolymers (Figures S1 and S2): S2

2. TGA curves of $\mathrm{T}_{95} \mathrm{~S}_{62} \mathrm{O}_{46} \mathrm{~S}_{62} \mathrm{~T}_{95}, \mathrm{~T}_{105} \mathrm{~S}_{60} \mathrm{O}_{90} \mathrm{~S}_{60} \mathrm{~T}_{105}$ and $\mathrm{T}_{107} \mathrm{~S}_{65} \mathrm{O}_{136} \mathrm{~S}_{65} \mathrm{~T}_{107}$ pentablock terpolymers (Figure S3): S3

3. TEM images of $\mathrm{T}_{95} \mathrm{~S}_{62} \mathrm{O}_{46} \mathrm{~S}_{62} \mathrm{~T}_{95}$ (a) stained with $\mathrm{OsO}_{4}$, (b) stained with $\mathrm{RuO}_{4}$. (Figure S4): S3

4. Additional TEM images of $\mathrm{T}_{105} \mathrm{~S}_{60} \mathrm{O}_{90} \mathrm{~S}_{60} \mathrm{~T}_{105}$ sample. (Figure S5): S4

5. The enlarged SAXS profiles of $\mathrm{T}_{105} \mathrm{~S}_{60} \mathrm{O}_{90} \mathrm{~S}_{60} \mathrm{~T}_{105}$ shown in the frame of Figure 7b (Figure S6): S5

*Corresponding author. E-mail: duby@zju.edu.cn. 


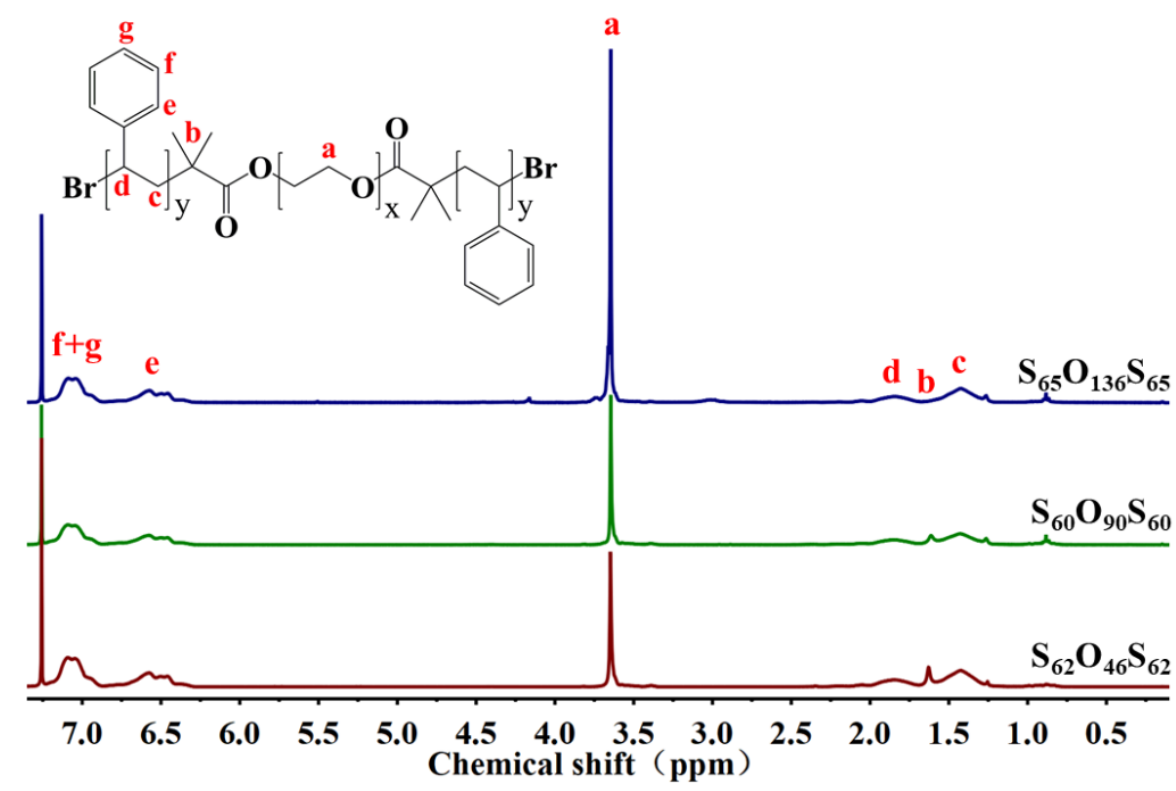

Figure S1. The ${ }^{1} \mathrm{H}$ NMR spectra of $\mathrm{S}_{62} \mathrm{O}_{46} \mathrm{~S}_{62}, \mathrm{~S}_{60} \mathrm{O}_{90} \mathrm{~S}_{60}$ and $\mathrm{S}_{65} \mathrm{O}_{136} \mathrm{~S}_{65}$ triblock copolymers.

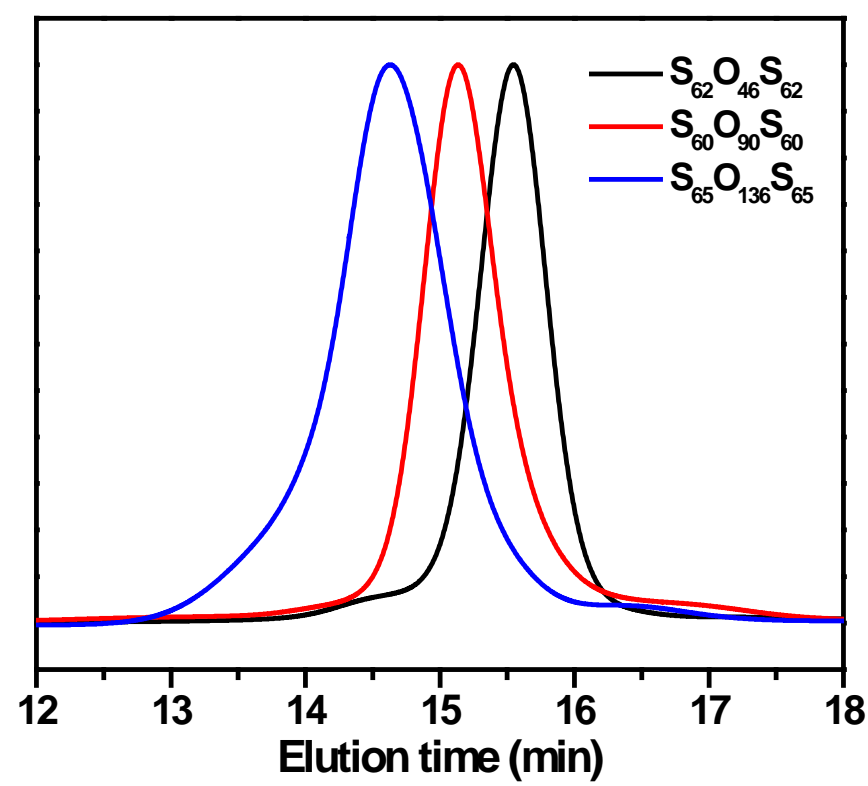

Figure S2. The GPC traces of $\mathrm{S}_{62} \mathrm{O}_{46} \mathrm{~S}_{62}, \mathrm{~S}_{60} \mathrm{O}_{90} \mathrm{~S}_{60}$ and $\mathrm{S}_{65} \mathrm{O}_{136} \mathrm{~S}_{65}$ triblock copolymers. 


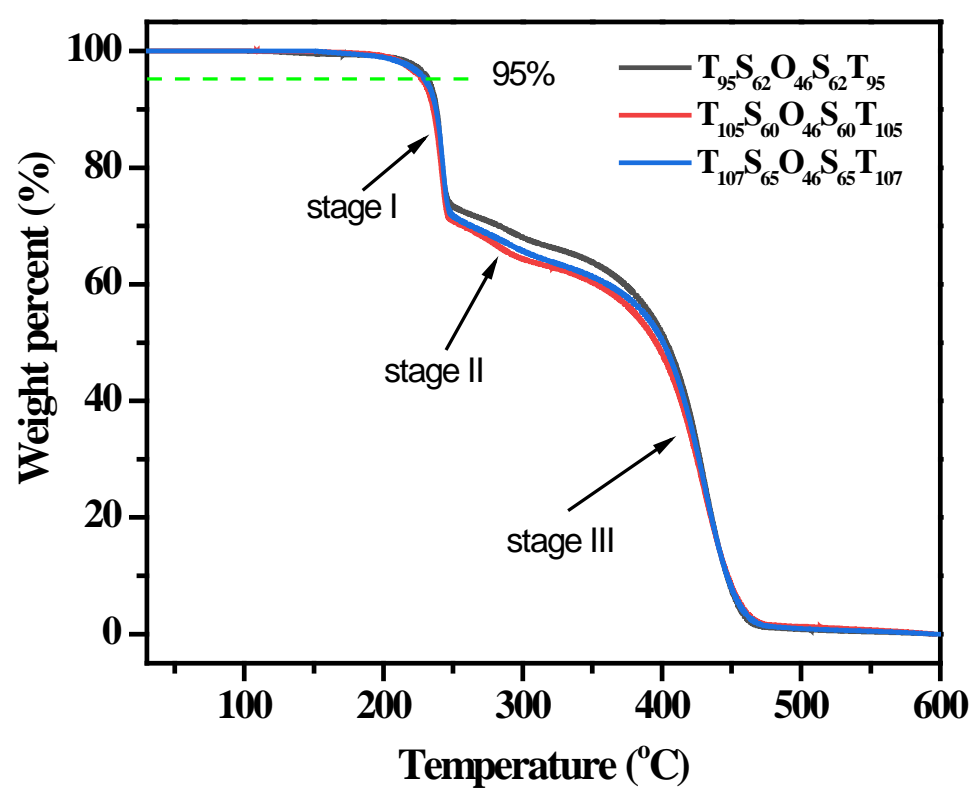

Figure S3. TGA curves of $\mathrm{T}_{95} \mathrm{~S}_{62} \mathrm{O}_{46} \mathrm{~S}_{62} \mathrm{~T}_{95}, \mathrm{~T}_{105} \mathrm{~S}_{60} \mathrm{O}_{90} \mathrm{~S}_{60} \mathrm{~T}_{105}$ and $\mathrm{T}_{107} \mathrm{~S}_{65} \mathrm{O}_{136} \mathrm{~S}_{65} \mathrm{~T}_{107}$ pentablock terpolymers.
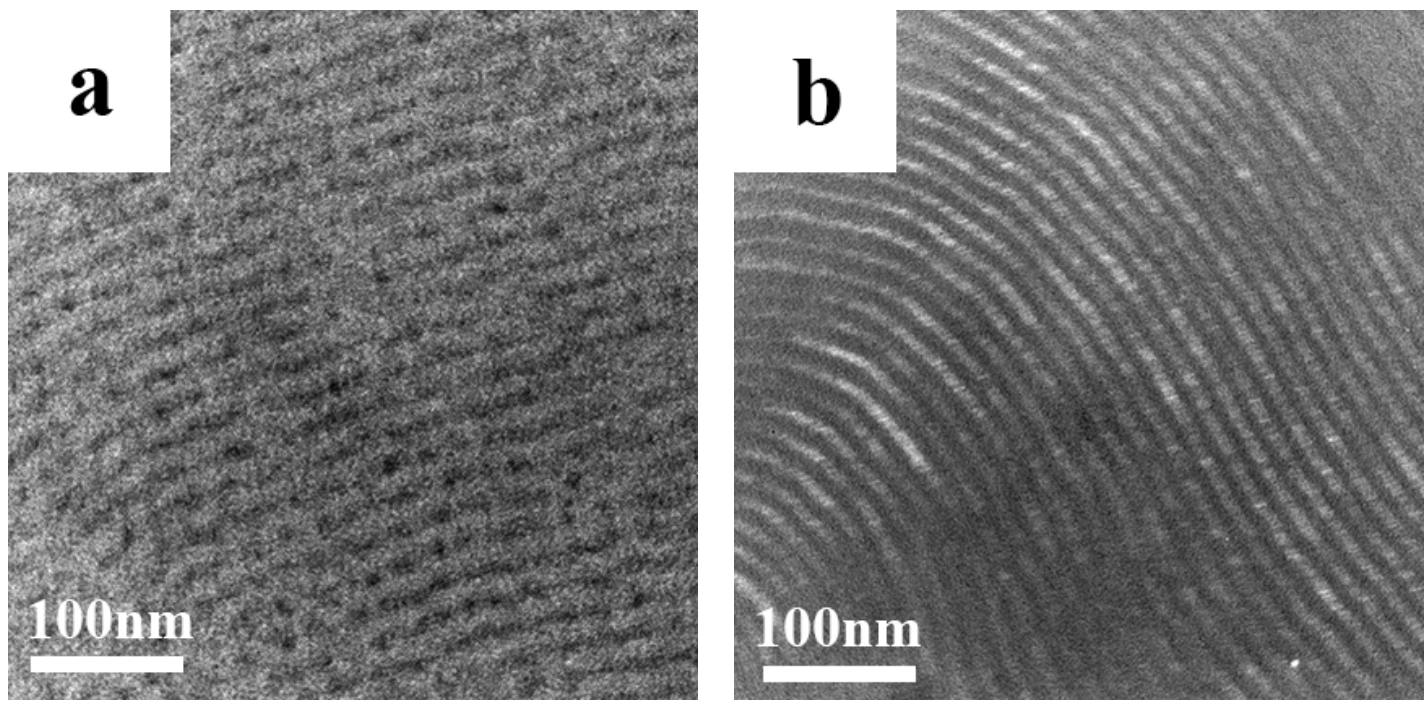

Figure S4. TEM images of $\mathrm{T}_{95} \mathrm{~S}_{62} \mathrm{O}_{46} \mathrm{~S}_{62} \mathrm{~T}_{95}$ (a) stained with $\mathrm{OsO}_{4}$, (b) stained with $\mathrm{RuO}_{4}$. 

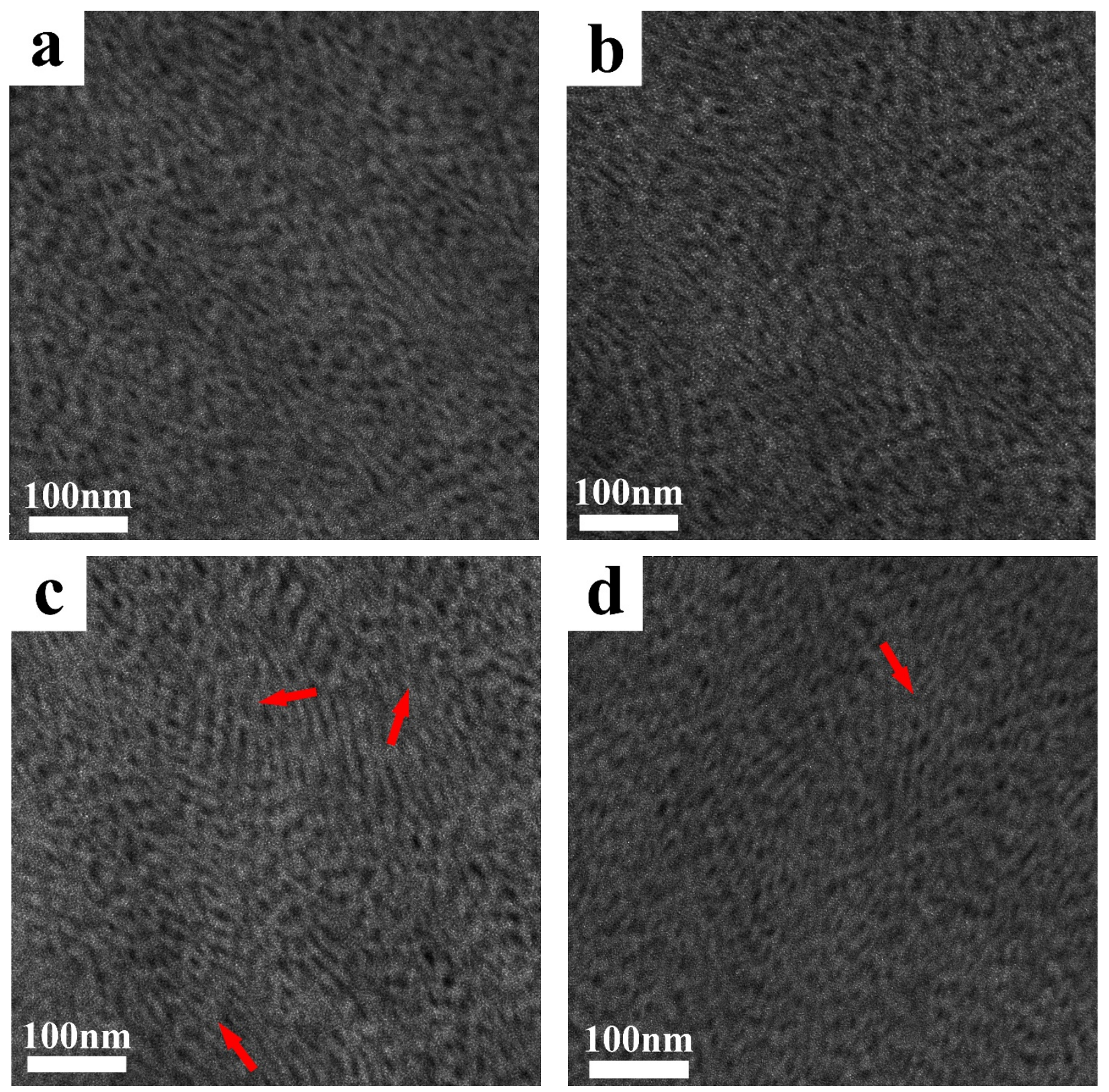

Figure S5. Additional TEM images of $\mathrm{T}_{105} \mathrm{~S}_{60} \mathrm{O}_{90} \mathrm{~S}_{60} \mathrm{~T}_{105}$ sample. The [111] projections with certain distortion, were observed, which indicate the formation of gyroid structure. The distortion of [111] projects might be caused by the shearing force induced during the slicing process. The red arrows in (c) and (d) point to the [111] projections. 


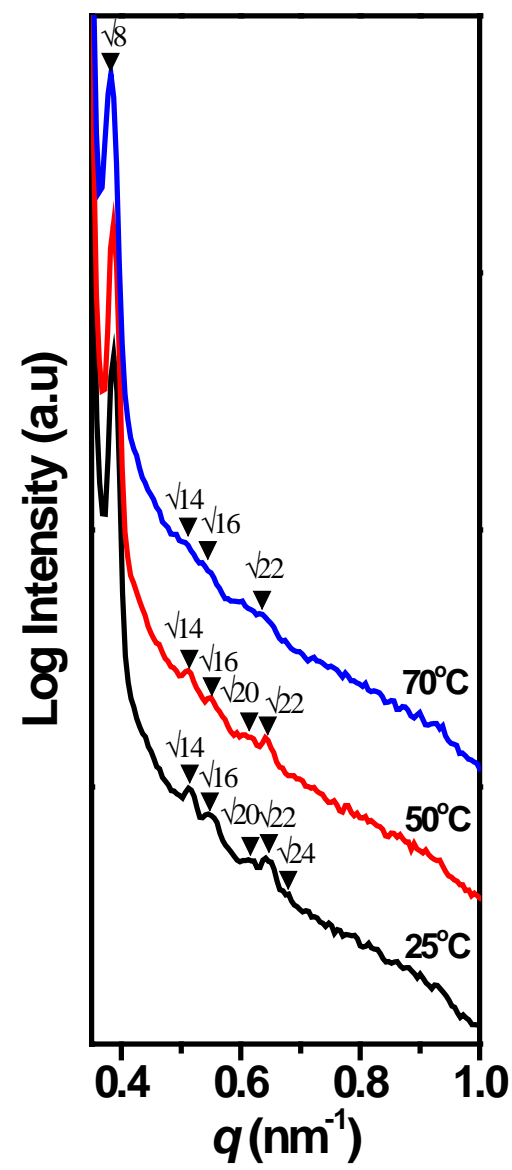

Figure S6. The enlarged SAXS profiles of $\mathrm{T}_{105} \mathrm{~S}_{60} \mathrm{O}_{90} \mathrm{~S}_{60} \mathrm{~T}_{105}$ shown in the frame of Figure $7 \mathrm{~b}$. 